\title{
Comparative Study between Magnetite Nanoparticles and Magnetite/Silver as a Core/Shell Nanostructure
}

\author{
Nabiha I. Abdo \\ Higher Institute of Engineering and Technology, New Borg Al Arab City, Alexandria, Egypt \\ Email: nabiha_ibrhim@yahoo.com
}

How to cite this paper: Abdo, N.I. (2021) Comparative Study between Magnetite Nanoparticles and Magnetite/Silver as a Core/ Shell Nanostructure. Advances in Nanoparticles, 10, 115-122.

https://doi.org/10.4236/anp.2021.104008

Received: November 5, 2021

Accepted: November 27, 2021

Published: November 30, 2021

Copyright $\odot 2021$ by author(s) and Scientific Research Publishing Inc. This work is licensed under the Creative Commons Attribution International License (CC BY 4.0).

http://creativecommons.org/licenses/by/4.0/

\begin{abstract}
Magnetite nanoparticles (MNPs) and magnetite/silver nanoparticles (M/Ag $\mathrm{NPs}$ ) were synthesized by chemical co-precipitation of $\mathrm{Fe}^{2+}$ and $\mathrm{Fe}^{3+}$. In case of M/Ag NPs, MNPs (core) were separately coated by silver metal (shell) in presence of glucose as a reducing agent. The particle size and morphology of the nanoparticles were characterized by dynamic light scattering (DLS) and scanning electron microscopy (SEM). Magnetic properties were investigated by vibrating sample magnetometry (VSM). The superparamagnetic natures of the nanoparticles were confirmed by the absence of the hysteresis loop. Coverage with silver produced a core-shell heterostructure which weakens magnetization of MNPs, inducing an inert character to the final nanostructure. The surface conjugation of MNPs with silver metal has been employed in order to improve the compatibility of magnetite nanoparticles to overcome their limitations in practical applications.
\end{abstract}

\section{Keywords}

Magnetite Nanoparticles (MNPs), $\mathrm{Fe}_{3} \mathrm{O}_{4}$, Silver Metal, Core/Shell, DLS, SEM, VSM

\section{Introduction}

During the last few years, magnetite $\left(\mathrm{Fe}_{3} \mathrm{O}_{4}\right)$ nanoparticles have been attracting interest, especially in the area of clinical-oriented medical applications, such as diagnosis [1] [2], hyperthermia cancer treatment [3] or combating iron deficiencies [4]. This was possible due to their properties like biocompatibility [5] [6] [7] [8], biodegradability [9] [10] [11], magnetic behaviour [12] [13] and the possibility of easy functionalization [14] [15]. Other possible uses of these 
nanoparticles might be in fields like catalysis [16] [17], environmental remediation [18] [19] [20] [21], electronics [22] [23] [24].

The chemical methods for synthesis offer the advantage that the resulting nanoparticles can be functionalized at the end of the process, which ensures improved stability compared to non-functionalized materials and conservation of magnetic properties. One of the most common and easiest chemical methods for magnetite nanoparticles synthesis is the co-precipitation developed by Massartin 1981 [25].

Metallic bonds are chemical bonds that form between metal elements. It is very rare that this interaction takes place between the $\mathrm{Fe}$ atoms in the oxide structure of magnetite and other metals, when developing core-shell metallic nanoparticles. So, the current study purposed to synthesize and then characterize MNPs and M/Ag NPs [ $\left(\mathrm{Fe}_{3} \mathrm{O}_{4}\right)$ core- $(\mathrm{Ag})$ shell] by using DLS, SEM and VSM as a comparative study.

\section{Experimental}

\subsection{Materials}

Ferric chloride hexahydrate $\left(\mathrm{FeCl}_{3} \cdot 6 \mathrm{H}_{2} \mathrm{O}\right)$, ferrous sulphate hexahydrate (Fe$\mathrm{SO}_{4} \cdot 6 \mathrm{H}_{2} \mathrm{O}$ ), ammonia solution, silver nitrate and glucose were purchased from Sigma-Aldrich. All chemical reagents used in the experiments were used without any further purification.

\subsection{Preparation of Magnetite Nanoparticles (MNPs) and M/Ag NPs [( $\left.\mathrm{Fe}_{3} \mathrm{O}_{4}\right)$ Core-(Ag) Shell]}

Magnetite nanoparticles (MNPs) and magnetite/silver nanoparticles (M/Ag NPs) were prepared as reported previously [26] [27]. Magnetite nanoparticles (MNPs) were synthesized by chemical coprecipitation of $\mathrm{Fe}^{2+}(1 \mathrm{~mol})$ and $\mathrm{Fe}^{3+}(2$ mol) with the addition of $\mathrm{NH}_{4} \mathrm{OH}(30 \mathrm{wt} \%) . \mathrm{M} / \mathrm{Ag} \mathrm{NPs}\left[\left(\mathrm{Fe}_{3} \mathrm{O}_{4}\right)\right.$ core- $(\mathrm{Ag})$ shell $]$ is by directly reducing $\mathrm{Ag}^{+}$ions on the surface of the $\mathrm{Fe}_{3} \mathrm{O}_{4}$ nanoparticles, using reducing agents such as glucose.

\subsection{Characterization}

\subsubsection{Dynamic Light Scattering}

The average size was examined by means of dynamic light scattering (DLS, Zetasizer Nano-ZS, Malvern Instruments, London, UK).

\subsubsection{Scanning Electron Microscopy}

The morphology of powder sample of $\mathrm{Fe}_{3} \mathrm{O}_{4}$ nanoparticles was analyzed using scanning electron microscopy (JEOL SEM, JSM-636OLA, Japan) at an accelerated voltage $20 \mathrm{kV}$.

\subsubsection{Vibrating Sample Magnetometer}

Magnetic characteristics were measured by VSM (Lake Shore-7410 vibrating sample magnetometer, USA), magnetic field up to 30,000 Oe. 


\section{Results and Discussion}

Dynamic Light Scattering (DLS): DLS, also known as photon correlation spectroscopy, is one of the most popular methods used to determine the size of MNPs. During the DLS measurement, the MNPs suspension is exposed to a light beam (electromagnetic wave), and as the incident light impinges on the MNPs, the direction and intensity of the light beam are both altered due to a process known as scattering [28].

The hydrodynamic radius is the radius of a sphere that has the same diffusion coefficient within the same viscous environment of the particles being measured. It is directly related to the diffusive motion of the particles.

MNPs and M/Ag NPs size distributions via dynamic light scattering are shown in Figure 1 and Figure 2. The mean particle size measured at angle (forward angle $11^{\circ}$ ) of synthesized MNPs and M/Ag NPs were 10.6 and $20 \mathrm{~nm}$, respectively. Hydrodynamic size of M/Ag NPs greater than MNPs, which is a strong evidence for extra layers attached on the surface of magnetite core. Measurement at angle (side scattering $90^{\circ}$ ), it found that the mean particle size of each has a higher value with a broad range (the variation of the intensity with time) which means high distribution range of particles after silver coating on MNPs surface.

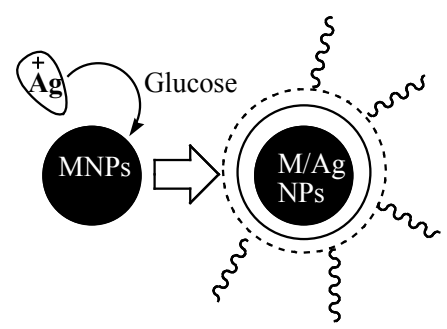

可 1.dat Unimodal Results Summary

\begin{tabular}{|c|c|c|c|c|c|c|}
\hline Angle & $\begin{array}{c}\text { Mean } \\
(\mathrm{nm})\end{array}$ & P.I. & $\begin{array}{c}\text { Diff.Coef } \\
\left(\mathrm{m}^{2} / \mathrm{s}\right)\end{array}$ & Counts/s & $\begin{array}{c}\text { Baseline } \\
\text { Error }\end{array}$ & Overflow \\
\hline $11.1^{\circ}$ & 10.6 & -3.656 & $4.05 e-11$ & $4.28 e+05$ & $0.11 \%$ & 0 \\
\hline $90.0^{\circ}$ & 177.0 & -1.386 & $2.42 e-12$ & $4.04 e+06$ & $0.00 \%$ & 0 \\
\hline
\end{tabular}

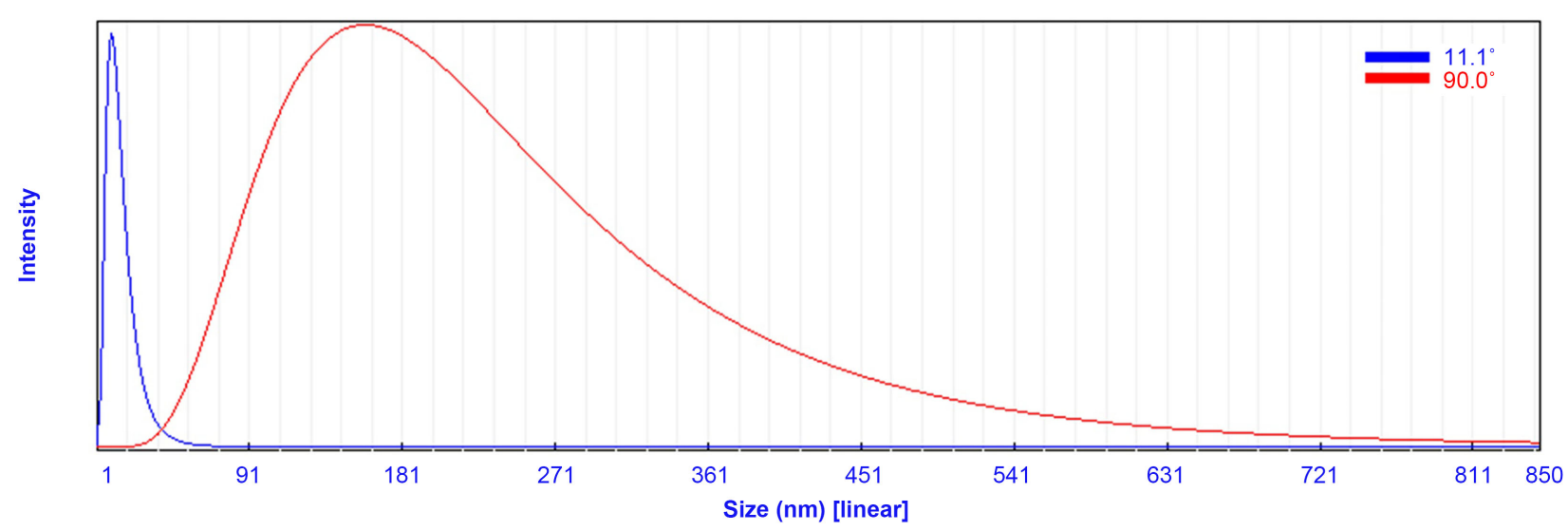

Figure 1. MNPs size distribution via dynamic light scattering. 
NAB Unimodal Results Summary

\begin{tabular}{|c|c|c|c|c|c|c|}
\hline Angle & $\begin{array}{c}\text { Mean } \\
(\mathrm{nm})\end{array}$ & P.I. & $\begin{array}{c}\text { Diff.Coef } \\
\left(\mathrm{m}^{2} / \mathrm{s}\right)\end{array}$ & Counts/s & $\begin{array}{c}\text { Baseline } \\
\text { Error }\end{array}$ & Overflow \\
\hline $11.1^{\circ}$ & 20.0 & -0.705 & $2.14 \mathrm{e}-11$ & $2.10 e+06$ & $0.78 \%$ & 0 \\
\hline $90.0^{\circ}$ & 1009.8 & -12.184 & $4.24 \mathrm{e}-13$ & $4.56 e+06$ & $0.44 \%$ & 0 \\
\hline
\end{tabular}

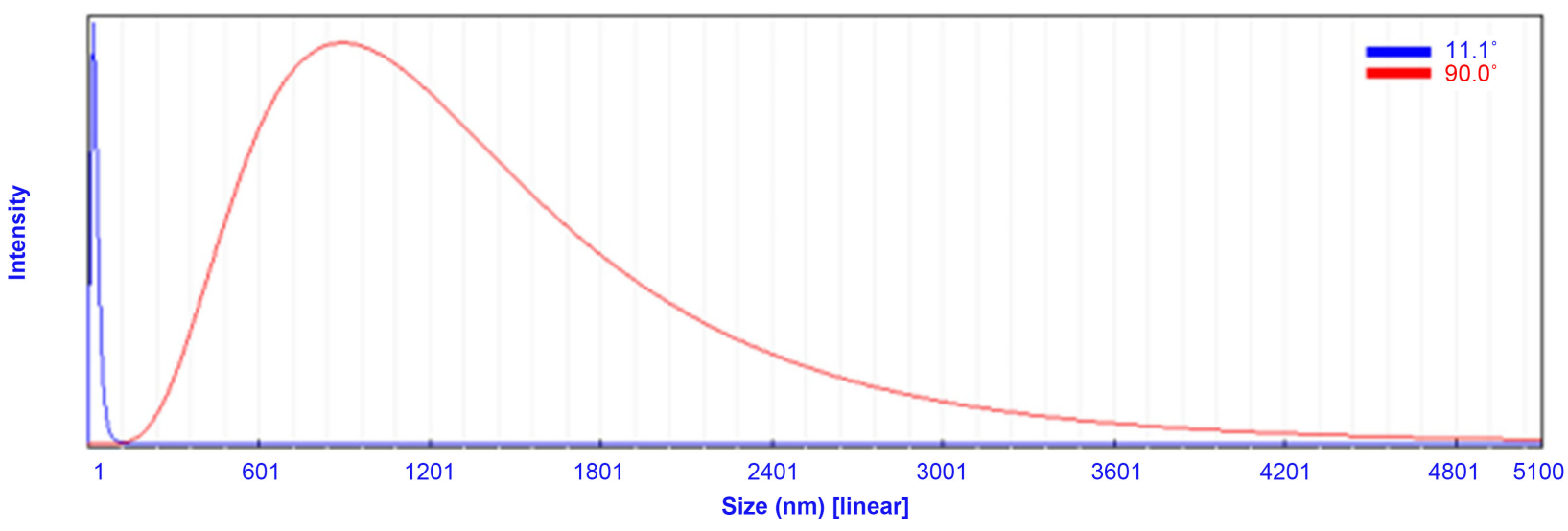

Figure 2. M/Ag NPs size distribution via dynamic light scattering.

Based on particle size, small particles move quickly with fast decay (driving forces on them are the same) but large particles move more slowly and therefore the decay is delayed (larger friction force with solvent) which is related to their diffusion coefficients [29]. So, coating silver may promote surface properties with good dispersion and aggregation stability to MNPs core carrier. Additionally, indicating good physical contacts between the target materials and the hybrid nanoparticles which consider useful in many applications.

SEM analysis: The SEM micrographs of MNPs and M/Ag NPs are shown in Figure 3(a) and Figure 3(b). The scanning electron micrograph of MNPs (Figure 3(a)) shows smooth clusters of particles together and the aggregates are slightly spherical in shape. The micrograph of M/Ag NPs (Figure 3(b)) shows more compact particles aggregates with an improved surface. Clearly, the SEM data serve as visual and descriptive evidence for the formation of $\mathrm{Fe}_{3} \mathrm{O}_{4} / \mathrm{Ag}$ core-shell nanoparticles.

Magnetic analysis (VSM): Magnetic properties of MNPs and M/Ag NPs were studied previously [26] [27] with a magnetometer with vibrating sample (a maximum applied field of $30 \mathrm{k} \mathrm{Oe}$ ) at ambient temperature. The changes in the magnetization with the applied magnetic field are presented in Figure 4.

The superparamagnetic natures of the nanoparticles were confirmed by the absence of the hysteresis loop. There was a decrease in the saturation magnetization after coating MNPs (core) with Ag (shell). This indicates that the coverage with silver weakens magnetization of MNPs, which diminishes magnetic properties for the M/Ag NPs and inducing an inert character to the final nanostructure.

The superparamagnetic of MNPs (core) with silver (shell) can be a potential candidate to effectively applications with recyclable capability and minimum release into environment. 


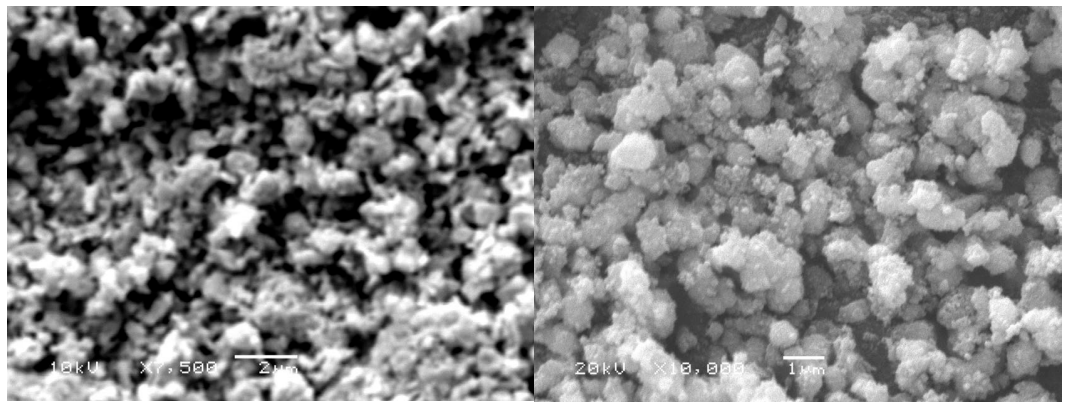

(a)

(b)

Figure 3. SEM micrographs: (a) Pure MNPs; (b) MNPs after coating Ag metal.

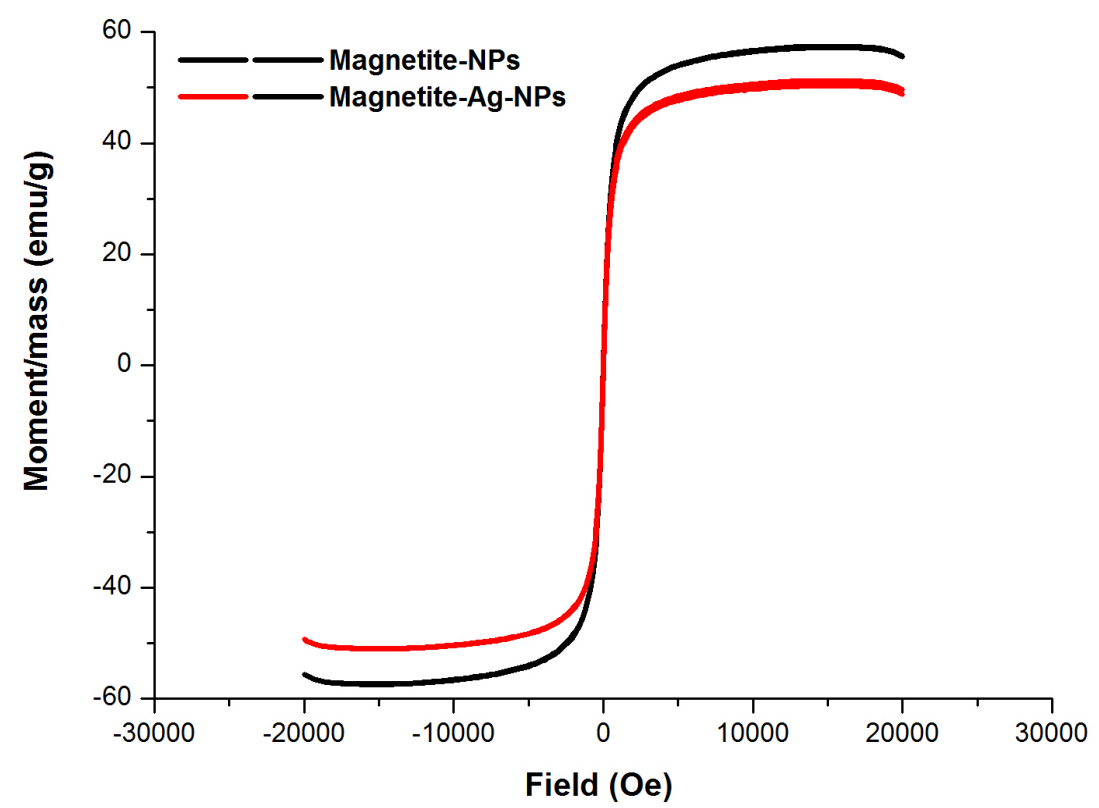

Figure 4. The relation between the applied magnetic field $(\mathrm{H})(\mathrm{Oe})$ and the magnetization $(\mathrm{M})(\mathrm{emu} / \mathrm{g})$ of MNPs and M/Ag NPs.

\section{Conclusion}

Magnetite nanoparticles (MNPs) were synthesized using the coprecipitation method. The direct route to obtaining this type of nano-composites $\mathrm{M} / \mathrm{Ag} \mathrm{NPs}$ $\left[\left(\mathrm{Fe}_{3} \mathrm{O}_{4}\right)\right.$ core- $(\mathrm{Ag})$ shell] is by directly reducing $\mathrm{Ag}^{+}$ions on the surface of the $\mathrm{Fe}_{3} \mathrm{O}_{4}$ nanoparticles, using reducing agents such as glucose. According to DLS, coating silver may promote surface properties with good dispersion and aggregation stability to the MNPs core carrier. SEM data serve as visual and descriptive evidence for the formation of $\mathrm{Fe}_{3} \mathrm{O}_{4} / \mathrm{Ag}$ core-shell nanoparticles. Coverage with silver produced a core-shell heterostructure which weakens magnetization of MNPs, inducing an inert character to the final nanostructure.

\section{Conflicts of Interest}

The author declares no conflicts of interest regarding the publication of this paper. 


\section{References}

[1] AMAG Pharmaceuticals. https://www.amagpharma.com/our-products/

[2] Wáng, Y.X.J. and Idée, J.M. (2017) A Comprehensive Literatures Update of Clinical Researches of Superparamagnetic Resonance Iron Oxide Nanoparticles for Magnetic Resonance Imaging. Quantitative Imaging in Medicine and Surgery, 7, 88-122.

[3] MagForce. Fighting Cancer with Nanomedicine.

http://www.magforce.de/en/home.html

[4] Feraheme (Ferumoxytol Injection). https://www.feraheme.com/dosing-administration/

[5] Zhang, D. and Du, Y. (2006) The Biocompatibility Study of $\mathrm{Fe}_{3} \mathrm{O}_{4}$ Magnetic Nanoparticles Used in Tumor Hyperthermia. Proceedings of the 20061 st IEEE International Conference on Nano/Micro Engineered and Molecular Systems, Zhuhai, 18-21 January 2006, 339-342. https://doi.org/10.1109/NEMS.2006.334754

[6] Chen, D., Tang, Q., Li, X., Zhou, X., Zhang, J., Xue, W.Q., Xiang, J.Y. and Guo, C.Q. (2012) Biocompatibility of Magnetic $\mathrm{Fe}_{3} \mathrm{O}_{4}$ Nanoparticles and Their Cytotoxic Effect on MCF-7 Cells. International Journal of Nanomedicine, 7, 4973-4982. https://doi.org/10.2147/IJN.S35140

[7] Sun, J., Zhou, S., Hou, P., Yang, Y., Weng, J. Li, X. and Li, M. (2007) Synthesis and Characterization of Biocompatible $\mathrm{Fe}_{3} \mathrm{O}_{4}$ Nanoparticles. Journal of Biomedical Materials Research, 80A, 333-341. https://doi.org/10.1002/jbm.a.30909

[8] Tian, Q., Ning, W., Wang, W., Yuan, X. and Bai, Z. (2016) Synthesis of SizeControllable $\mathrm{Fe}_{3} \mathrm{O}_{4}$ Magnetic Sub Micro Particles and Its Biocompatible Evaluation in Vitro. Journal of Central South University, 23, 2784-2791.

https://doi.org/10.1007/s11771-016-3341-4

[9] Tseng, W.K., Chieh, J.J., Yang, Y.F., Chiang, C.K., Chen, Y.L., Yang, S.Y., Horng, H.E., Yang, H.C. and Wu, C.C. (2012) A Noninvasive Method to Determine the Fate of $\mathrm{Fe}_{3} \mathrm{O}_{4}$ Nanoparticles Following Intravenous Injection Using Scanning SQUID Biosusceptometry. PLOS ONE, 7, e48510. https://doi.org/10.1371/journal.pone.0048510

[10] Gu, L., Fang, R.H., Sailor, M.J. and Park, J.H. (2012) In Vivo Clearance and Toxicity of Monodisperse Iron Oxide Nanocrystals. ACS Nano, 6, 4947-4954. https://doi.org/10.1021/nn300456z

[11] Yew, Y.P., Shameli, K., Miyake, M., Khairudin, N.B.B.A., Mohamad, S.E.B., Naiki, T. and Lee, K.X. (2018) Green Biosynthesis of Superparamagnetic Magnetite $\mathrm{Fe}_{3} \mathrm{O}_{4}$ Nanoparticles and Biomedical Applications in Targeted Anticancer Drug Delivery System: A Review. Arabian Journal of Chemistry, 13, 2287-2308.

[12] Patsula, V., Moskvin, M., Dutz, S. and Horák, D. (2016) Size-Dependent Magnetic Properties of Iron Oxide Nanoparticles. Journal of Physics and Chemistry of Solids, 88, 24-30. https://doi.org/10.1016/j.jpcs.2015.09.008

[13] Li, Q., Kartikowati, C.W., Horie, S., Ogi, T., Iwaki, T. and Okuyama, K. (2017) Correlation between Particle Size/Domain Structure and Magnetic Properties of Highly Crystalline $\mathrm{Fe}_{3} \mathrm{O}_{4}$ Nanoparticles. Scientific Reports, 7, Article No. 9894. https://doi.org/10.1038/s41598-017-09897-5

[14] Darwish, M.S.A., Nguyen, N.H.A., Ševcu, A. and Stibor, I. (2015) Functionalized Magnetic Nanoparticles and Their Effect on Escherichia coli and Staphylococcus aureus. Journal of Nanomaterials, 2015, Article ID: 416012. https://doi.org/10.1155/2015/416012 
[15] Wu, W., He, Q. and Jiang, C. (2008) Magnetic Iron Oxide Nanoparticles: Synthesis and Surface Functionalization Strategies. Nanoscale Research Letters, 3, Article No. 397. https://doi.org/10.1007/s11671-008-9174-9

[16] Li, Z.X., Luo, D., Li, M.M., Xing, X.F., Ma, Z.Z. and Xu, H. (2017) Recyclable $\mathrm{Fe}_{3} \mathrm{O}_{4}$ Nanoparticles Catalysts for Aza-Michael Addition of Acryl Amides by Magnetic Field. Catalysts, 7, Article No. 219. https://doi.org/10.3390/catal7070219

[17] Alishiri, T., Oskooei, H.A. and Heravi, M.M. (2013) $\mathrm{Fe}_{3} \mathrm{O}_{4}$ Nanoparticles as an Efficient and Magnetically Recoverable Catalyst for the Synthesis of $\alpha, \beta$-Unsaturated Heterocyclic and Cyclic Ketones under Solvent-Free Conditions. Synthetic Communications, 43, 3357-3362.

https://doi.org/10.1080/00397911.2013.786089

[18] Araújo, R., Castro, A.C.M. and Fiúza, A. (2015) The Use of Nanoparticles in Soil and Water Remediation Processes. Materials Today. Proceedings, 2, 315-320. https://doi.org/10.1016/j.matpr.2015.04.055

[19] Jiang, B., Lian, L., Xing, Y., Zhang, N., Chen, Y., Lu, P. and Zhang, D. (2018) Advances of Magnetic Nanoparticles in Environmental Application: Environmental Remediation and (Bio) Sensors as Case Studies. Environmental Science and Pollution Research, 25, 30863-30879. https://doi.org/10.1007/s11356-018-3095-7

[20] Gutierrez, A.M., Dziubla, T.D. and Hilt, J.Z. (2017) Recent Advances on Iron Oxide Magnetic Nanoparticles as Sorbents of Organic Pollutants in Water and Wastewater Treatment. Reviews on Environmental Health, 32, 111-117. https://doi.org/10.1515/reveh-2016-0063

[21] Abobakr, S.M., Abdo, N.I. and Mansour, R.A. (2020) Remediation of Contaminated Water with Crystal Violet Dye by Using Magnetite Nanoparticles: Synthesis, Characterization and Adsorption Mechanism Studies. Journal of Environmental Studies, 6, 1-10. https://doi.org/10.13188/2471-4879.1000029

[22] De Teresa, J.M., Fernández-Pacheco, A., Morellon, L., Orna, J., Pardo, J.A., Serrate, D., Algarabel, P.A. and Ibarra, M.R. (2007) Magneto Transport Properties of $\mathrm{Fe}_{3} \mathrm{O}_{4}$ Thin Films for Applications in Spin Electronics. Microelectronic Engineering, 84, 1660-1664. https://doi.org/10.1016/j.mee.2007.01.120

[23] Guo, L., Sun, H., Qin, C., Li, W., Wang, F., Song, W., Du, J., Zhong, F. and Ding, Y. (2018) Flexible $\mathrm{Fe}_{3} \mathrm{O}_{4}$ Nanoparticles/N-Doped Carbon Nano Fibers Hybrid Film as Binder-Free Anode Materials for Lithium-Ion Batteries. Applied Surface Science, 459, 263-270. https://doi.org/10.1016/j.apsusc.2018.08.001

[24] Salimi, P., Norouzi, O. and Pourhosseini, S.E.M. (2019) Two-Step Synthesis of Nanohusk $\mathrm{Fe}_{3} \mathrm{O}_{4}$ Embedded in 3D Network Pyrolytic Marine Biochar for a New Generation of Anode Materials for Lithium-Ion Batteries. Journal of Alloys and Compounds, 786, 930-937. https://doi.org/10.1016/j.jallcom.2019.02.048

[25] Massart, R. (1981) Preparation of Aqueous Magnetic Liquids in Alkaline and Acidic Media. IEEE Transactions on Magnetics, 17, 1247-1248. https://doi.org/10.1109/TMAG.1981.1061188

[26] Abdo, N.I., Abobakr, S.M., Abd El-Wahab, A.E. and El-Deeb, N.M. (2019) Superparamagnetic Iron Oxide Nanoparticles with Antimicrobial Activities: Synthesis and Characterization of Stable Dispersion of $\mathrm{Fe}_{3} \mathrm{O}_{4}$ in DMSO/Citric Acid. Advanced Science, Engineering and Medicine, 11, 783-788.

https://doi.org/10.1166/asem.2019.2412

[27] Beltagy, D.M., Tousson, E., Abdo, N.I. and Izzularab, B.M. (2021) Protective Effect of Chicory (Chichorium intybus L.) Extract against Renal Toxicity Induced by 
Magnetite Silver Nanoparticles in Male Rats. Online Journal of Biological Sciences, 21, 251-260. https://doi.org/10.3844/ojbsci.2021.251.260

[28] Van de Hulst, H.C. (1981) Light Scattering by Small Particles. Dover Publications, New York.

[29] Hiemenz, P.C. and Rajagopalan, R. (1997) Principles of Colloid and Surface Chemistry. 3rd Edition, Marcel Dekker, New York. 